\title{
MAGE-A4-specific TCR Gene-transduced Autologous T Lymphocytes TBI-1201
}

National Cancer Institute

\section{Source}

National Cancer Institute. MAGE-A4-specific TCR Gene-transduced Autologous T

Lymphocytes TBI-1201. NCI Thesaurus. Code C114978.

Autologous human T-lymphocytes transduced with a retroviral vector encoding a T-cell receptor (TCR) specific for the human melanoma antigen A4 (MAGE-A4), with potential immunostimulatory and antineoplastic activities. Upon isolation, transduction, expansion ex vivo, and reintroduction into the patient, MAGE-A4-specific TCR gene-transduced Tlymphocytes TBI-1201 binds to tumor cells expressing MAGE-A4. This may result in both an inhibition of growth and increased cell death for MAGE-A4-expressing tumor cells. The tumor-associated antigen MAGE-A4 is overexpressed by a variety of cancer cell types. 